\title{
The predictors of post-partum depression in a tertiary centre
}

\author{
Sadiq Unnisa*, Poluri Seetha Lavanya
}

Department of Obstetrics and Gynecology, Yenepoya Medical College, Mangalore, Karnataka, India

Received: 14 January 2018

Revised: 07 February 2018

Accepted: 30 April 2018

\section{*Correspondence:}

Dr. Sadiq Unnisa,

E-mail: drsadiqa12@gmail.com

Copyright: (c) the author(s), publisher and licensee Medip Academy. This is an open-access article distributed under the terms of the Creative Commons Attribution Non-Commercial License, which permits unrestricted non-commercial use, distribution, and reproduction in any medium, provided the original work is properly cited.

\section{ABSTRACT}

Background: The present study was undertaken to evaluate the association of different socio-demographic, obstetric and pregnancy outcome as predictor of PPD among the postnatal women during early puerperium and thus can be provided with special care. Objective was to evaluate the different predictors of post partum depression.

Methods: A prospective study was conducted in the department of obstetrics and gynaecology, Yenepoya medical college hospital Mangalore. A total of 200 postnatal mothers in their 3rd - 7th postpartum day were interrogated using Edinburgh postnatal depression scale (EPDS). Socio-demographic factors like age, parity, literary, socio economic status, family structure, obstetric outcome was recorded. Results were statistically analyzed with chi-square test.

Results: A prospective study was conducted in the Department of Obstetrics and Gynaecology, Yenepoya Medical College Hospital, Mangalore. A total of 200 postnatal mothers in their 3rd - 7th postpartum day were interrogated using Edinburgh postnatal depression scale (EPDS). Socio-demographic factors like age, parity, literary, socio economic status, family structure, obstetric outcome was recorded. Results were statistically analyzed with chi-square test.

Conclusions: Risk of PPD is more with the birth of a female baby, women who had CS, low S.E status, unemployment could predict higher risk for PPD. PPD screening should be an integral part of postnatal care using E PDS routinely. A multidisciplinary approach including obstetrician and psychiatrists can be jointly care of the depressed mothers.

Keywords: EPDS scale, Postpartum depression, Predictors

\section{INTRODUCTION}

Postnatal or postpartum period is considered as high-risk period for the emergence of psychiatric disorders. Postpartum depression (PPD) is one of the most common psychopathological disorder during pregnancy and postnatal period. PPD includes non-psychotic depressive episode, with loss of interest, insomnia and loss of energy described by the mothers in the postnatal period. ${ }^{1}$ Range of PPD prevalence $(10-42 \%)$ has been reported worldwide. ${ }^{2}$ It is a serious health issue because of its effect on mothers, families, and infants and children. PPD has a multifactorial etiology encompassing demographic, economic, psychosocial, obstetric and medical risk factors.

Factors like birth of baby girl, protective influence of traditional rituals, financial insecurity, marital violence, lack of support have emerged as risk factors for PPD in low and medium income countries like, India, Pakistan.

The present study was undertaken to evaluate the association of different socio-demographic, obstetric and pregnancy outcome as predictor of PPD among the postnatal women during early puerperium and thus can be provided with special care. 


\section{METHODS}

A prospective study was conducted in OBG department, Yenepoya medical college hospital Mangalore. A total of 200 postnatal mothers in their 3rd-7th postpartum day were interrogated using Edinburgh postnatal depression scale (EPDS). ${ }^{3}$

The questionnaire comprised of ten questions. Women who scored more than 13 were considered to be suffering from depression. Socio-demographic factors like age, parity, socio economic status, family structure, occupation of the mother and her spouse, mode of delivery, obstetric outcome, and gender of the new born baby were recorded.

\section{Inclusion criteria}

- Postnatal mothers who were willing to participate in the study.

\section{Exclusion criteria}

- Mothers who had abortion, who had ectopic pregnancies and the mothers who were not willing to participate were excluded. Institutions review board and ethics committee approved the study protocol. Written informed consent was taken from all the responders.

\section{Statistical analysis}

Statistical analysis was done using chi square test.

\section{RESULTS}

The distribution of women with (score $>13$ ) and without (score <13) depression in various subgroups of each parameter considered are shown in Table 1. Age, parity, literacy showed no relationship with occurrence of PPD. Most of the women were Muslims by religion (Table 1).

Table 1: Distribution of patient with score (>13) and score (<13) PPD with reference to age, parity, religion, education and economic status.

\begin{tabular}{|c|c|c|c|c|c|}
\hline Parameter & & Score $<13$ & Score $>13$ & Total & P valve \\
\hline \multirow{5}{*}{ Age } & $<20$ & 8 & 8 & 16 & \multirow{5}{*}{$>0.05$} \\
\hline & $21-25$ & 35 & 53 & 88 & \\
\hline & $26-30$ & 37 & 34 & 71 & \\
\hline & $31-35$ & 7 & 10 & 17 & \\
\hline & $>35$ & 2 & 6 & 8 & \\
\hline \multirow{2}{*}{ Parity } & Primi & 38 & 44 & 82 & \multirow{2}{*}{$>0.05$} \\
\hline & Multi & 51 & 67 & 118 & \\
\hline \multirow{3}{*}{ Religion } & Christian & 0 & 1 & 1 & \multirow{3}{*}{$>0.05$} \\
\hline & Hindu & 18 & 16 & 34 & \\
\hline & Muslims & 71 & 94 & 165 & \\
\hline \multirow{3}{*}{ Education } & Illiterate & 5 & 14 & 19 & \multirow{3}{*}{$>0.05$} \\
\hline & Primary & 70 & 80 & 150 & \\
\hline & Secondary & 14 & 17 & 31 & \\
\hline \multirow[t]{2}{*}{ Economic status } & Below poverty & 50 & 12 & 62 & $<0.05$ \\
\hline & Above poverty & 132 & 6 & 138 & $<0.05$ \\
\hline
\end{tabular}

Table 2: Distribution of patient with score $(>13)$ and score $(<13)$ PPD with reference to family type, women's occupation, husband's occupation, mode of delivery and gender.

\begin{tabular}{|c|c|c|c|c|c|}
\hline Parameter & & Score $<13$ & Score $>13$ & Total & P valve \\
\hline \multirow{2}{*}{ Family type } & Joint & 3 & 7 & 10 & \multirow{2}{*}{$>0.05$} \\
\hline & Nuclear & 86 & 104 & 190 & \\
\hline \multirow[b]{2}{*}{ Women's occupation } & Employed & 20 & 11 & 31 & \multirow[b]{2}{*}{$<0.05$} \\
\hline & Unemployed & 69 & 100 & 169 & \\
\hline \multirow{3}{*}{ Husband's occupation } & Business & 32 & 21 & 43 & \multirow{3}{*}{$>0.05$} \\
\hline & Govt. Job & 25 & 26 & 51 & \\
\hline & Private job & 42 & 64 & 106 & \\
\hline \multirow{2}{*}{ Delivery } & Preterm & 6 & 6 & 12 & \multirow{2}{*}{$>0.05$} \\
\hline & Term & 83 & 105 & 188 & \\
\hline \multirow{2}{*}{ Mode of delivery } & Normal & 72 & 59 & 131 & \multirow{2}{*}{$<0.001$} \\
\hline & LSCS & 17 & 52 & 69 & \\
\hline \multirow[b]{2}{*}{ Gender } & Male & 72 & 39 & 111 & \multirow{2}{*}{$<0.001$} \\
\hline & Female & 17 & 72 & 89 & \\
\hline
\end{tabular}


Majority of the post-natal mothers belonged to nuclear family. Mothers who delivered at term gestation outnumbered the mothers who delivered at preterm gestation.

Women who underwent caesarean section (CS), women who delivered female baby, but desired male baby has statistically high significant relationship $(\mathrm{p}<0.001)$. Low Socio -economic status and women who were un employed showed just significant relationship with PPD. $(\mathrm{P}<0.05)$ (Table 1 and Table 2).

\section{DISCUSSION}

In the present study women who underwent $\mathrm{CS}$, women who delivered baby girl, but desired male baby, low SE, and unemployment showed great relationship with occurrence of PPD.

Age, parity, literacy, SE status, religion do have a significant influence on pregnancy and marital health in the present study in the present study. Mayberry et al have found younger women to be a risk factor for PPD, however Bjerke et al in their study found that age $>30$ years are associated with PPD.,

Berry $\mathrm{M}$ et al, Forman $\mathrm{N}$ et al have found an increased association of multipara with PPD whereas More B et al found primiparity to be associated with PPD. ${ }^{4,6,7}$ Like in our study, Josefsson et al have concluded that no association exists between parity and PPD. ${ }^{8}$

In present study women who had operative delivery (CS) had significant relationship with PPD. This was supported by studies of Adewuya et al and Bergant et al have found that delivery by $\mathrm{CS}$ to be a risk factor whereas studies of Josefsson et al found no such association. $^{8-10}$

Male child preference is deeply enriched in Indian culture, birth of baby girl is considered as a family and social stress and hence a strong predictor of PPD, our study and studies by Patel et al, Hedge $S$ et al and Chandran $\mathrm{M}$ et al, corroborate this gender bias. ${ }^{11-13}$ In the present study, authors found just significant association between PPD and socio-economic status having monthy income $<5000$ INR. Berry $M$ et al and Bergant et al have similar results, whereas Kosinska-Kazynska et al found no such relationship..$^{4,10,14}$

\section{CONCLUSION}

Risk of PPD is more with the birth of a female baby, women who had CS, low S.E status, unemployment could predict higher risk for PPD. PPD screening should be an integral part of postnatal care using E PDS routinely. A multidisciplinary approach including obstetrician and psychiatrists can jointly take care of the depressed mothers.

\section{ACKNOWLEDGMENTS}

Authors would like to thank all the postnatal mothers who took part in the study and Ms. Geetha for assistance in typing and statistician.

\section{Funding: No funding sources}

Conflict of interest: None declared

Ethical approval: The study was approved by the Institutional Ethics Committee

\section{REFERENCES}

1. World health organization international statistical classification of diseases and related health problems 10th Revision (ICD 10). Available at http://apps.who.int/classifications/apps/icd/icd10onli ne/Published 2007. Accessed 2014 Feb 21.

2. Pearlslein T, Howard M, Salisbury A, Ziorick C. Post partum depression. Am J Obstet Gynecol. 2009;200:357-64.

3. Cox JL, Holden JM, Sagovksy R. Detection of postnatal depression: development of the 10-item Edinburgh postnatal depression scale. $\mathrm{Br} \mathrm{J}$ Psychiatry. 1987;150:782-6.

4. Mayberry LH, Horowitz JA, Declercq E. Depression symptom prevalence and demographic risk factors among U.S. women during the first 2 years postpartum. J Obstet Gynecol Neonatal Nurs. 2007;36:542-9.

5. Bjerke SE, Vangen S, Nordhagen R, Ytterdahl T, Magnus P, Stray-Pedersen B, et al. Postpartum depression among Pakistani women in Norway: prevalence and risk factors. J Matern Fetal Neonatal Med. 2008;7:1-6.

6. Nielsen D, Videbech P, Hedegaard M, Dalby J, Secher NJ. Postpartum depression: identification of women at risk. BJOG. 2000;107:1210-7.

7. Blackmore ER, Jones I, Doshi M, Haque S, Holder $\mathrm{R}$, Brockington I, Craddock $\mathrm{N}$, et al. Obstetric variables associated with bipolar affective puerperal psychosis. Br J Psych. 2006;188:32-6.

8. Josefsson A, Angelsioo L, Berg G, Ekstrom CM, Gunnervik C, Nordin C, Sydsjo G, et al. Obstetric, somatic and demographic risk factors for postpartum depressive symptoms. Obstet Gynecol. 2002;99:2238 .

9. Adewuya AO, Fatoye FO, Ola BA, Ijaodola OR, Ibigbami SM. Sociodemographic and Obstetric risk factors for postpartum Depressive symptoms in Nigerian women. J Psychiatr Pract. 2005;11:353-8.

10. Bergant AM, Heim K, Ulmer H, Illmensee K. Early postnatal depressive mood: associations with obstetric and psychosocial factors. J Psychosom Res. 1999;46:391-4. 
11. Patel V, Rodrigues M, Desouza N. Gender, poverty, and postanatal depression: a study of mothers in Goa, India. Am J Psychiatry. 2002;159:43-7.

12. Hegde S, Latha KS, Bhat SM, Sharma PS, Kamath A. Postpartum Depression: Prevalance and Associated factors among women in India. J Women's Health, Issues Care. 2012;1(1):1-7.

13. Chandran $M$, Tharyan $\mathrm{P}$, Muliyil J, Abraham. Postpartu. Depression in cohort of women from a rural area of Tamil Nadu: incidence and risk factors. Br J Psyciatry. 2002;181:499-504.
14. Szymusik I, Wielgoś M, Horosz E, KosińskaKaczyńska K. Affective disorders in the first week after the delivery: prevalence and risk factors. Ginekol Pol. 2008;79:182-5.

Cite this article as: Unnisa S, Lavanya PS. The predictors of post partum depression in a tertiary centre. Int J Reprod Contracept Obstet Gynecol 2018;7:2218-21. 